\title{
Evolutionary Pattern and Intergenerational Transmission of Inequality in Human Capital
}

\author{
Yaqi Sun \\ Guanghua School of Management, Peking University, Beijing, China \\ Email: sunyaqi@pku.edu.cn
}

How to cite this paper: Sun, Y. Q. (2020). Evolutionary Pattern and Intergenerational Transmission of Inequality in Human Capital. Modern Economy, 11, 1421-1431. https://doi.org/10.4236/me.2020.118100

Received: July 1, 2020

Accepted: July 27, 2020

Published: July 30, 2020

Copyright (c) 2020 by author(s) and Scientific Research Publishing Inc. This work is licensed under the Creative Commons Attribution International License (CC BY 4.0).

http://creativecommons.org/licenses/by/4.0/

\begin{abstract}
This study investigates whether the inequality in human capital persists among generations in the framework of overlapping generation (OLG) model. Including different expectations for return on education investment into to OLG model and assuming that an individual's human capital is totally determined by education investment, we obtain the evolutionary pattern of inequality in education investment among successive generations and conducted numerical simulation. We find that when the rate of diminishing marginal return on education investment is low, the inequality in human capital persists in the long run and the human capital is polarized in equilibrium state. When the rate of diminishing marginal return on education investment is high, there exists convergence in human capital distribution and the inequality in human capital will disappear in the long run.
\end{abstract}

\section{Keywords}

Intergenerational Mobility, Inequality in Human Capital, Education Investment, Overlapping Generation Model

\section{Introduction}

Inequality has always been a hot issue in the field of economic and sociology research and there exists a large body of literature about the role of human capital plays in the intergenerational transmission of inequality in income and wealth (Becker and Tomes, 1979; Becker and Tomes, 1986; Becker, 1993; Solon, 1999; Mayer and Lopoo, 2005).

Some scholars believe that there exists income and wealth convergence and the inequality in income and wealth will not persist in the long run. Some previous studies (Bourguignon, 1981; Chatterjee, 1994; Caselli and Ventura, 2000; Li et al., 2000) show that if the market is perfect and there are no personal capac- 
ity difference and no continuous random shock, the inequality in income and wealth will eventually disappear over time. Loury (1981) and Tamura (1991) utilize general equilibrium framework to investigate the wealth distribution among generations under the condition that parents make human capital investment in their children and also find the existence of wealth convergence. Galor and Tsiddon (1997) construct a three-period OLG model and show that the externality of family environment will lead to polarization in wealth in the early stage but the wealth distribution will eventually converge as the impact of technology advance becomes greater in the long run.

Another strand of literature suggests that the inequality in wealth may persist in long term because of the imperfect capital market and labor market (Banerjee and Newman, 1993; Aghion and Bolton, 1997; Mookherjee and Ray, 2003). Galor and Zeira (1993) construct classic two-period OLG model and investigate the persistence of inequality in wealth under the assumption of credit market imperfections. They find that even if there is no personal capacity difference and no continuous random shock, the inequality in wealth persists in both short and long term.

As mentioned above, in the case of imperfect credit market, if parents' income and wealth are low, their investment in human capital for their children is also low, resulting in the children's low wealth level. Under this circumstance, the inequality in wealth has intergenerational persistence through the investment in human capital. Unlike the previous literature which focuses on the intergenerational transmission of inequality in income and wealth through the channel of human capital, our study investigates whether the inequality in human capital itself has intergenerational persistence.

We construct a three-period overlapping generation (OLG) model to explore this problem. Instead of assuming that the credit market is imperfect, we assume that the credit market is perfect. Meanwhile, we assume that there are no personal capacity difference and no continuous random shock. Most importantly, our key assumption is that parents with higher human capital have higher expectations for the return on education investment. This assumption is reasonable and can be supported by fruitful literature. Altonji and Dunn (1996) find that the human capital level of parents has a positive impact on children's education return. Attanasio and Kaufmann (2014) propose that parents' expectation for return on education investment affects their choice of education for their children. And this assumption plays a decisive role in the final result. Additionally, we assume that each individual's human capital is totally determined by the education investment received from their parents and individuals who receive high education investment will have high education level, that is to say, the inequality in human capital is the inequality in education investment. Therefore, we don't distinguish these two kinds of inequality in the following discussion.

Including different expectations for return on education investment into to OLG model and assuming that an individual's human capital is totally determined by education investment, we obtain the evolutionary pattern of inequality 
in education investment among successive generations and conducted numerical simulations. We find that when the rate of diminish marginal return on education investment is low, the inequality in human capital persists in the long run and the human capital is polarized in equilibrium state. When the rate of diminish marginal return on education investment is high, there exists convergence in human capital.

The rest of this paper is organized in the following way. Section 2 presents the theoretical model. In Section 3, we carry out some numerical simulations based on the three-period OLG model and interpret the results. Section 4 concludes and puts forward further research directions.

\section{Theoretical Model}

We conduct this research based on overlapping generation (OLG) model. Each individual lives three periods in this economy and has one offspring. That is, the total population remains constant. There is only one good which can be used for either investment or consumption.

Simply, it is assumed that in the first period (children period), the individual makes no consumption, depends on their parents for living, and needs to receive education investment from their parents, thus having a job in the second period. In the second period (youth period), the individual gains income and invests in education of his child. In the third period (old age period), the individual retires and lives on the deposit in the first period and the transfer payment from his child. It is assumed that the credit market is perfect. In other words, the individual can distribute wealth between the latter two periods by freely borrowing and lending at market interest rates. In this model, the individuals only care about the utility brought by their consumption in the latter two periods, and the discount rate is $\beta$. we use logarithmic form for the utility function, as shown in Formula (1)

$$
U=\log C_{i t}^{Y}+\beta \log C_{i t}^{O}
$$

where $i$ denotes the individual and $t$ denotes the period, the superscript $Y$ and $O$ denotes the youth period and old age period for an individual.

The investment of parents in children's education produces corresponding human capital according to a certain function, which has an impact on income. It is assumed that $e_{i t}$ is the education investment made by an individual in his youth period to his child in time $t$, and thus this investment enables his child to have the human capital $h_{i t+1}$ in time $t+1$. We assume that human capital is totally determined by the education investment received from their parents and individuals who receive high education investment will have high education level, that is to say, the inequality in human capital is the inequality in education investment.

$$
h_{i t+1}=h\left(e_{i t}\right)
$$

It is assumed that the production function is a simple Cobb-Douglas function, 
where $K$ represents the total capital, $L$ is the total effective labor which is calculated according to the human capital level.

$$
F(K, L)=A K_{t}^{\alpha} L_{t}^{1-\alpha}
$$

Then, interest rate $r$ and effective labor wage $w_{0}$ is as follows:

$$
\begin{gathered}
r=\alpha k_{t}^{1-\alpha} \\
w_{0}=(1-\alpha) k_{t}^{\alpha}
\end{gathered}
$$

In the model, the key assumption lies in that parents with different educational attainment have different expectations for returns on education investment. The meaning of difference in expectations is as follows. For the youth in period $t$, if he invests $e_{i t}$ in his child, his child with $h\left(e_{i t}\right)$ will obtain the income of $w_{0} h\left(e_{i t}\right)$. However, when parents make decision about their education investment for their children, they expect their children's income will be $w_{0} h\left(e_{i t}\right) \frac{h\left(e_{i t-1}\right)}{\bar{h}_{t-1}}$. It can be noted that $\frac{h\left(e_{i t-1}\right)}{\bar{h}_{t-1}}$ is the ratio of parents' human capital level to the average human capital level of their period. This ratio is used to measure the relative level of parents' education in the same period. Then, this ratio is multiplied with the actual income to measure the different expectations for returns on education investment. The higher an individual's education level is, the higher his expectation for returns on education investment in his child is. The transfer payment from a child to his parent is proportional to his income, and the proportion is $\tau$. Under these assumptions, the optimization problem faced by the youth in the $t$ period is:

$$
\begin{aligned}
& \max _{C_{i t}^{Y}, C_{i t}^{Y}, e_{i t}} \log C_{i t}^{Y}+\beta \log C_{i t}^{O} \\
& \text { s.t. } \quad C_{i t}^{Y}+e_{i t}+\frac{C_{i t}^{O}}{1+r} \leq w_{0} h\left(e_{i t-1}\right)+\frac{\tau w_{0} h\left(e_{i t}\right)}{1+r} * \frac{h\left(e_{i t-1}\right)}{\bar{h}_{t-1}}
\end{aligned}
$$

Solving this optimizations problem, we could obtain the necessary first order condition as follows.

$$
\begin{gathered}
\frac{C_{i t}^{O}}{C_{i t}^{Y}}=\beta(1+r) \\
h^{\prime}\left(e_{i t}\right)=\frac{(1+r) \bar{h}_{t-1}}{\tau w_{0} h\left(e_{i t-1}\right)} \\
w_{0} h\left(e_{i t-1}\right)+\frac{h\left(e_{i t}\right)}{h^{\prime}\left(e_{i t}\right)}-e_{i t}-C_{i t}^{Y}-\beta C_{i t}^{O}=0
\end{gathered}
$$

Our focus is on the evolutionary process of human capital distribution among generations, and we assume that human capital is totally determined by the education investment received from parents. That is, the discussion about the human capital distribution is the discussion of the education investment distribution. Therefore, the emphasis is on Formula (8). To simplify the calculation, a 
small open economy is assumed, that is, the interest rate $r$ is exogenous and fixed. From Formulas (4) and (5) we could see that $w_{0}$ is also constant under the assumption of small open economy. Specifically, it is assumed that $h(e)=e^{\gamma}$ and the following formula could be derived from Formula (8)

$$
e=\left\{\frac{(1+r) \bar{h}_{t-1}}{\tau w_{0} e_{i t-1}^{\gamma}}\right\}^{\frac{1}{\gamma-1}} .
$$

\section{Numerical Simulation}

Even under the assumptions mentioned above, it is difficult to make a direct derivation of distribution of $e_{i t}$ among successive generations. Therefore, the numerical simulation method is used to understand its evolutionary process and how it is affected by the values of the parameters.

We firstly take a simple case that there are two types of individuals with different education level. In the initial state, the proportion of individuals with high level education is $p$, and the proportion of individuals with low level education is $1-p$. Some specific values are assigned to the key variables mentioned above, as shown in Table 1.

By assigning these values to the key variables, the model is more realistic. And the assignment is in accordance with some classic papers. In fact, the assignment could be adjusted and exerts little impact on the results. Most importantly, the parameter exerting key influence on the result is $\gamma$, Reviewing the assumption above: $h(e)=e^{\gamma}$. On one hand, $\gamma$ directly affects the income resulted from education investment; on the other hand, it reflects the rate of diminishing marginal returns on education investment, exerting a significant impact on investment decision. The higher $\gamma s$, the lower the rate of diminishing marginal returns on education investment. We assume that $0<\gamma<0$, that is, $h^{\prime}(e)>0$, $h^{\prime \prime}(e)<0$. In the following numerical simulation, we assign the values of 0.2 , $0.4,0.5,0.6$ and 0.8 respectively to $\gamma$.

Table 2 shows the results of numerical simulation. From Table 2, we could find that the education investment of two types of individuals finally converges to the same equilibrium level when $\gamma$ is assigned as 0.2 and 0.4 and the convergence speed is even faster when $\gamma=0.2$. When $\gamma$ is 0.5 , the inequality in education investment between these two types of individuals will persist among generations and there are two kinds of education investment in the equilibrium

Table 1. Variable assignment.

\begin{tabular}{cc}
\hline Varibale & Value \\
\hline$R$ & 0.1 \\
$W_{0}$ & 5 \\
$p$ & 0.5 \\
$\tau$ & 0.2
\end{tabular}


Table 2. Results of numerical simulation.

\begin{tabular}{|c|c|c|c|c|c|c|c|c|c|c|}
\hline & \multicolumn{2}{|c|}{$\gamma=0.2$} & \multicolumn{2}{|c|}{$\gamma=0.4$} & \multicolumn{2}{|c|}{$\gamma=0.5$} & \multicolumn{2}{|c|}{$\gamma=0.6$} & \multicolumn{2}{|c|}{$\gamma=0.8$} \\
\hline & $\begin{array}{l}\text { high } \\
\text { level }\end{array}$ & $\begin{array}{l}\text { low } \\
\text { level }\end{array}$ & $\begin{array}{l}\text { high } \\
\text { level }\end{array}$ & $\begin{array}{l}\text { low } \\
\text { level }\end{array}$ & $\begin{array}{l}\text { high } \\
\text { level }\end{array}$ & $\begin{array}{l}\text { low } \\
\text { level }\end{array}$ & $\begin{array}{l}\text { high } \\
\text { level }\end{array}$ & $\begin{array}{l}\text { low } \\
\text { level }\end{array}$ & $\begin{array}{l}\text { high } \\
\text { level }\end{array}$ & $\begin{array}{l}\text { low } \\
\text { level }\end{array}$ \\
\hline 1 & 1.5 & 1.2 & 1.5 & 1.2 & 1.5 & 1.2 & 1.5 & 1.2 & 1.5 & 1.2 \\
\hline 2 & 1.6444 & 1.5552 & 1.531 & 1.3194 & 1.4892 & 1.1914 & 1.4559 & 1.0418 & 1.4241 & 0.5833 \\
\hline 3 & 1.5483 & 1.5269 & 1.4664 & 1.3279 & 1.4928 & 1.1942 & 1.6205 & 0.9808 & 4.4036 & 0.1239 \\
\hline 4 & 1.551 & 1.5456 & 1.4485 & 1.3558 & 1.4916 & 1.1933 & 1.7898 & 0.8428 & 17.1155 & 0 \\
\hline 5 & 1.546 & 1.5446 & 1.429 & 1.3674 & 1.492 & 1.1936 & 2.0795 & 0.672 & 19.8694 & 0 \\
\hline 6 & 1.546 & 1.5456 & 1.4184 & 1.3774 & 1.4919 & 1.1935 & 2.502 & 0.4596 & 19.8695 & 0 \\
\hline 7 & 1.5457 & 1.5456 & 1.4107 & 1.3833 & 1.4919 & 1.1935 & 3.082 & 0.2426 & 19.8695 & 0 \\
\hline 8 & 1.5457 & 1.5457 & 1.4057 & 1.3875 & 1.4919 & 1.1935 & 3.728 & 0.0824 & 19.8695 & 0 \\
\hline 9 & 1.5457 & 1.5457 & 1.4023 & 1.3902 & 1.4919 & 1.1935 & 4.217 & 0.0138 & 19.8695 & 0 \\
\hline 10 & 1.5457 & 1.5457 & 1.4001 & 1.392 & 1.4919 & 1.1935 & 4.4187 & 0.0008 & 19.8695 & 0 \\
\hline 11 & 1.5457 & 1.5457 & 1.3986 & 1.3932 & 1.4919 & 1.1935 & 4.4552 & 0 & 19.8695 & 0 \\
\hline 12 & 1.5457 & 1.5457 & 1.3976 & 1.394 & 1.4919 & 1.1935 & 4.4575 & 0 & 19.8695 & 0 \\
\hline 13 & 1.5457 & 1.5457 & 1.397 & 1.3946 & 1.4919 & 1.1935 & 4.4575 & 0 & 19.8695 & 0 \\
\hline 14 & 1.5457 & 1.5457 & 1.3965 & 1.3949 & 1.4919 & 1.1935 & 4.4575 & 0 & 19.8695 & 0 \\
\hline 15 & 1.5457 & 1.5457 & 1.3962 & 1.3952 & 1.4919 & 1.1935 & 4.4575 & 0 & 19.8695 & 0 \\
\hline 16 & 1.5457 & 1.5457 & 1.3961 & 1.3953 & 1.4919 & 1.1935 & 4.4575 & 0 & 19.8695 & 0 \\
\hline 17 & 1.5457 & 1.5457 & 1.3959 & 1.3954 & 1.4919 & 1.1935 & 4.4575 & 0 & 19.8695 & 0 \\
\hline 18 & 1.5457 & 1.5457 & 1.3958 & 1.3955 & 1.4919 & 1.1935 & 4.4575 & 0 & 19.8695 & 0 \\
\hline 19 & 1.5457 & 1.5457 & 1.3958 & 1.3956 & 1.4919 & 1.1935 & 4.4575 & 0 & 19.8695 & 0 \\
\hline 20 & 1.5457 & 1.5457 & 1.3957 & 1.3956 & 1.4919 & 1.1935 & 4.4575 & 0 & 19.8695 & 0 \\
\hline
\end{tabular}

state. When $\gamma=0.6$ and $\gamma=0.8$, the inequality in education investment will be much greater.

Therefore, it is speculated that there is a critical point $\gamma_{0}$ between 0.4 and 0.5 . When $\gamma<\gamma_{0}$, the inequality in education investment will disappear in the long run, and all individuals will converge to the same level of education investment and same level of human capital. There exists no intergenerational transmission of inequality in human capital. The smaller $\gamma$ is, the faster the convergence speed will be. Besides, when $\gamma>\gamma_{0}$, the inequality will persist in the long run. In this case, the larger $\gamma$ is, the larger the inequality gap is; and when $\gamma$ is greater than a certain threshold between 0.5 and 0.6 , individuals with low education level will invest nothing in their next generation's education. This finding conforms to the intuitive reasoning. The value of $\gamma$ represents the rate of diminishing marginal return on education investment. When $\gamma$ is very small, the return gained from marginal education investment decreases rapidly, even the individuals with high education level lack the incentives to invest more in education, and the gap in education investment will continue to narrow until the gap disappears. But this 
trend will not exist when $\gamma$ is greater than a certain point.

We also take a more complex case. It is assumed that education investment in the initial state obeys normal distribution with a mean of 1.35 and a standard deviation of 0.15 (the mean and standard deviation are the same as two types of individuals mentioned above). Figure 1 shows this initial distribution of education investment. $\gamma, w_{0}$ and $\tau$ are assumed to follow the settings in Table 1. 1000 random numbers are taken as initial population samples according to the normal distribution of $\mathrm{N}(1.35,0.15)$. We investigate the evolutionary pattern of education investment distribution of these samples in the next 20 periods and draw frequency distribution histogram.

Similarly, we assign the values of $0.2,0.4,0.5,0.6$ and 0.8 respectively to $\gamma$. Figures 2-6 show the distribution of education investment in the 10th and 20th generation in different settings of $\gamma$.

From Figure 2, it can be seen that when $\gamma$ is taken as 0.2 , the education investment of the population will soon converges to about 0.8877 , which can be predicted to eventually converges to the same equilibrium level. Besides, Figure 3

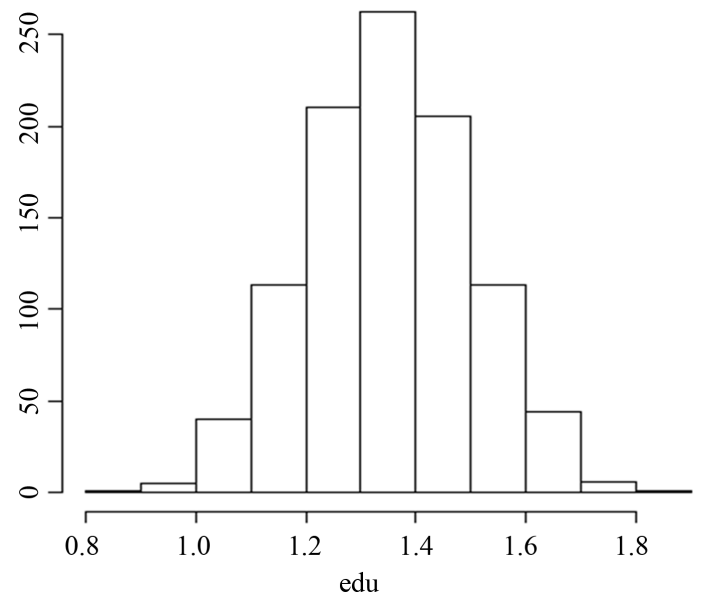

Figure 1. The initial distribution of education investment (normal distribution of $\mathrm{N}$ $(1.35,0.15))$.

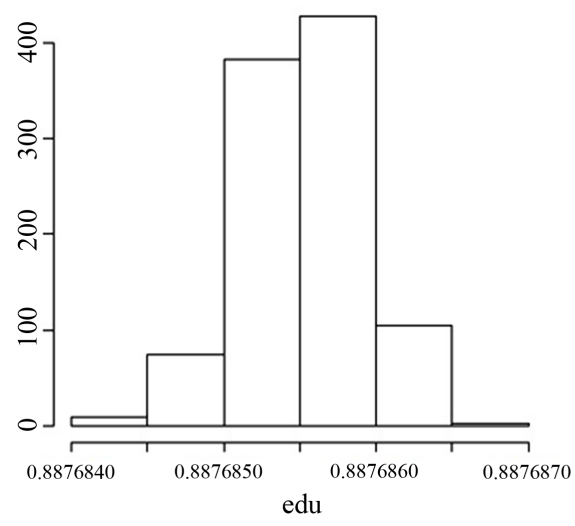

10th generation

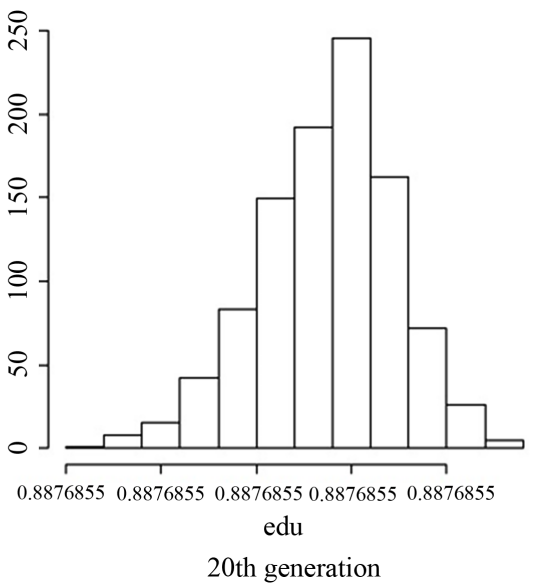

20th generation

Figure 2. When $\gamma=0.2$. 


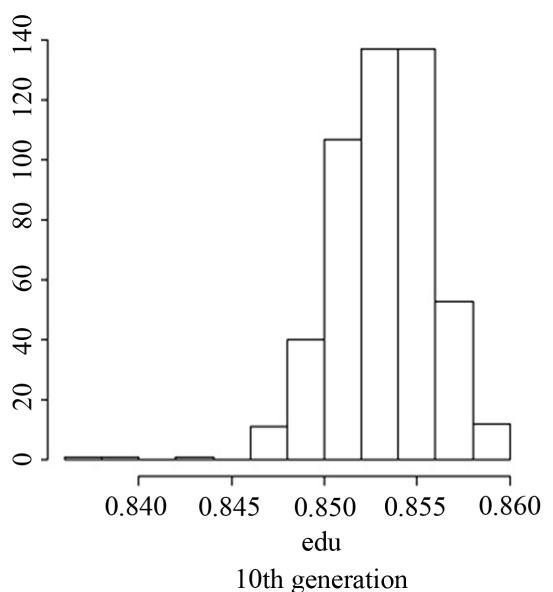

Figure 3. When $\gamma=0.4$.

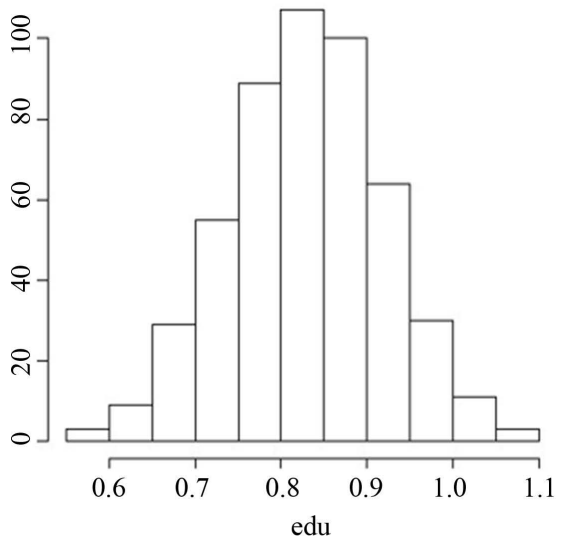

10th generation

Figure 4. When $\gamma=0.5$.

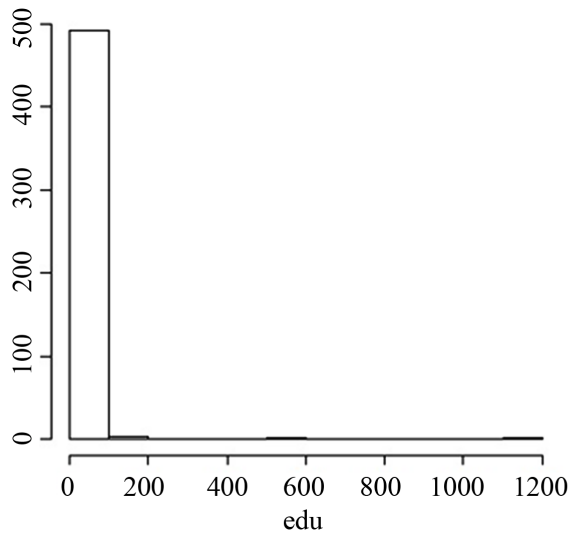

10th generation
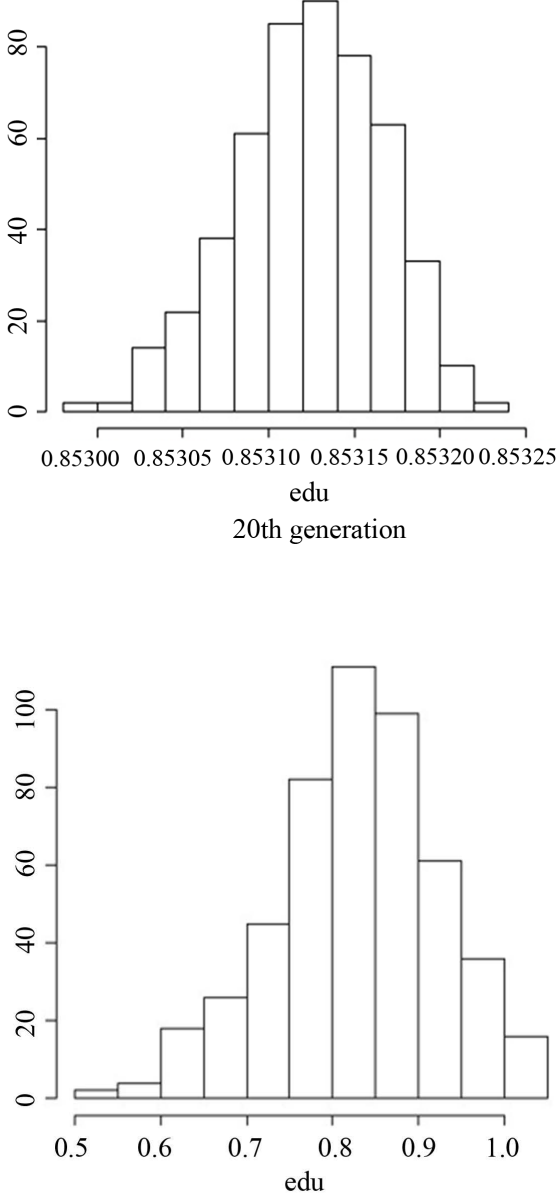

20th generation

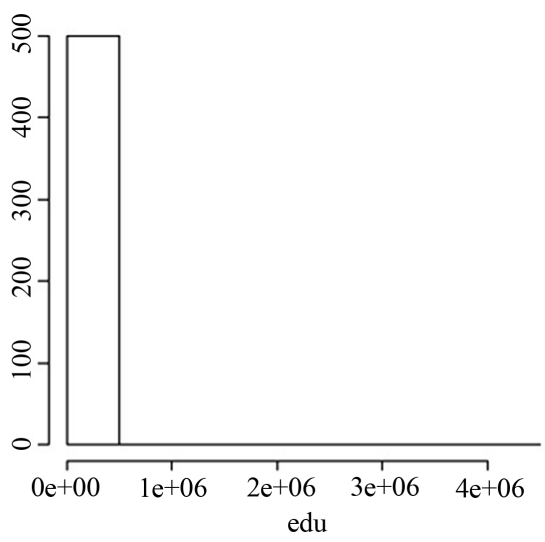

20th generation

Figure 5. When $\gamma=0.6$.

shows that when $\gamma=0.4$, the convergence speed is relatively slow so the education investment doesn't concentrate well in 10th generation, but the education investment of total population soon concentrates around 0.853 in 20th 


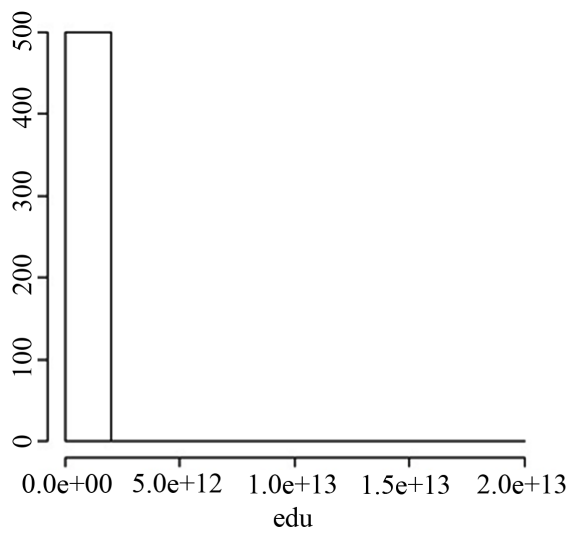

10th generation

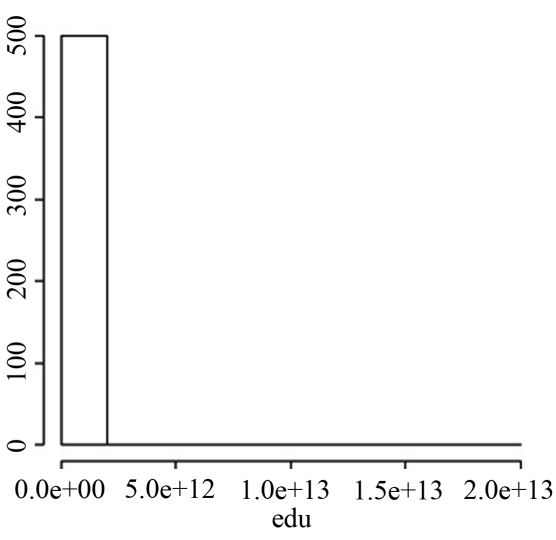

20th generation

Figure 6. When $\gamma=0.8$.

generation, which can be predicted that the education investment is same in the final equilibrium state. In Figure 5 and Figure 6, the values of $\gamma$ are 0.6 and 0.8 respectively. Actually, in 10th and 20th generations, the education investment of most people is 0 , and only few people have high level of education investment, indicating an obvious polarization in education investment in long-term equilibrium state. That is, the intergenerational transmission of inequality in human capital exists when the rate of diminishing marginal return on education investment is low enough. In Figure 4, when $\gamma=0.5$, the distribution of education investment in 10th and 20th generations obeys normal distribution to a large extent. However, It is difficult to decide whether it is because the normal distribution will become a long-term equilibrium state when $\gamma$ is in a certain range near 0.5 , or because the convergence speed is too slow. Therefore, more periods are needed to explore the case that $\gamma$ is in a certain range near 0.5. Also, this is the further research direction in the future.

\section{Conclusion and Further Research}

We analyze whether the inequality in human capital itself has intergenerational persistence based on three-period overlapping generation model. After including different expectations for return on education investment into to OLG model and assuming that an individual's human capital is totally determined by education investment he received, we obtain the evolutionary pattern of inequality in education investment among successive generations as is shown in Formula (8) and conducted numerical simulation.

We conduct two kinds of numerical simulations. In the first simulation, we assume two types of individuals with high education level and low education level respectively. In the second simulation, the education investment of the population in the initial state is subject to normal distribution. Our simulation analysis shows that when the rate of diminishing marginal return on education investment is low, the inequality in human capital persists in the long run and the human capital is polarized in equilibrium state. When the rate of diminish- 
ing marginal return on education investment is high, there exists convergence in human capital distribution and the inequality in human capital will disappear in the long run.

Our study is at a preliminary level and there are some deficiencies in this paper. On one hand, we assume education investment in the initial state obeys normal distribution while it may not conform to the reality. On the other hand, we assume the interest rate is exogenous and sometimes it is a too strong assumption. Further research could be conducted in the following direction. Firstly, it is very interesting and important to provide credible support for the conclusion of this paper through rigorous mathematical reasoning. Secondly, we could try more precise numerical simulation and obtain more useful information where the mathematical reasoning power is beyond reach. For example, other different initial distributions like uniform distribution can be tried to study whether the distribution in equilibrium depends on the distribution of initial state. Thirdly, the assumptions in the model can be relaxed. To simplify the discussion, it is assumed that the interest rate is exogenous. By contrast, later research can examine the case that interest rate is endogenous, thus further explore the impact of this inequality in human capital on consumption, welfare, savings and other variables.

\section{Conflicts of Interest}

The author declares no conflicts of interest regarding the publication of this paper.

\section{References}

Aghion, P., \& Bolton, P. (1997). A Theory of Trickle-Down Growth and Development. The Review of Economic Studies, 64, 151-172. https://doi.org/10.2307/2971707

Altonji, J. G., \& Dunn, T. A. (1996). The Effects of Family Characteristics on the Return to Education. The Review of Economics and Statistics, 78, 692-704. https://doi.org/10.2307/2109956

Attanasio, O., \& Kaufmann, K. M. (2014). Education Choices and Returns to Schooling: Mothers' and Youths' Subjective Expectations and Their Role by Gender. Journal of Development Economics, 109, 203-216. https://doi.org/10.1016/j.jdeveco.2014.04.003

Banerjee, A., \& Newman, A. F. (1993). Occupational Choice and the Process of Development. Journal of Political Economy, 101, 274-298. https://doi.org/10.1086/261876

Becker, G. S. (1993). Nobel Lecture: The Economic Way of Looking at Behavior. Journal of Political Economy, 101, 385-409. https://doi.org/10.1086/261880

Becker, G. S., \& Tomes, N. (1979). An Equilibrium Theory of the Distribution of Income and Intergenerational Mobility. Journal of Political Economy, 87, 1153-1189. https://doi.org/10.1086/260831

Becker, G. S., \& Tomes, N. (1986). Human Capital and the Rise and Fall of Families. Journal of Labor Economics, 4, 257-298. https://doi.org/10.1086/298118

Bourguignon, F. (1981). Pareto Superiority of Unegalitarian Equilibria in Stiglitz' Model of Wealth Distribution with Convex Saving Function. Econometrica, 49, 1469-1475. https://doi.org/10.2307/1911412 
Caselli, J., \& Ventura, C. J. (2000). A Representative Consumer Theory of Distribution. American Economic Review, 90, 909-926. https://doi.org/10.1257/aer.90.4.909

Chatterjee, S. (1994). Transitional Dynamics and the Distribution of Wealth in a Neoclassical Growth Model. Journal of Public Economics, 54, 97-119. https://doi.org/10.1016/0047-2727(94)90072-8

Galor, O., \& Tsiddon, D. (1997). The Distribution of Human Capital and Economic Growth. Journal of Economic Growth, 2, 93-124. https://doi.org/10.1023/A:1009785714248

Galor, O., \& Zeira, J. (1993). Income Distribution and Macroeconomics. The Review of Economic Studies, 60, 35-52. https://doi.org/10.2307/2297811

Li, H., Xie, D., \& Zou, H. F. (2000). Dynamics of Income Distribution. The Canadian Journal of Economics, 33, 937-961. https://doi.org/10.1111/0008-4085.00048

Loury, G. C. (1981). Intergenerational Transfers and the Distribution of Earnings. Econometrica, 49, 843-867. https://doi.org/10.2307/1912506

Mayer, S. E., \& Lopoo, L. M. (2005). Has the Intergenerational Transmission of Economic Status Changed. Journal of Human Resources, 40, 169-185. https://doi.org/10.3368/jhr.XL.1.169

Mookherjee, D., \& Ray, D. (2003). Persistent Inequality. The Review of Economic Studies, 70, 369-393. https://doi.org/10.1111/1467-937X.00248

Solon, G. (1999). Chap. 29. Intergenerational Mobility in the Labor Market. In Handbook of Labor Economics (Vol. 3, pp. 1761-1800). Amsterdam: Elsevier B.V. https://doi.org/10.1016/S1573-4463(99)03010-2

Tamura, R. F. (1991). Income Convergence in an Endogenous Growth Model. Journal of Political Economy, 99, 522-540. https://doi.org/10.1086/261765 